\title{
Lithium Electroactivity of Cobalt Oxide Nanoparticles Synthesized Using Thermolysis Process
}

\author{
Yun-Ho Jin, Hyun-Woo Shim, and Dong-Wan Kim ${ }^{\dagger}$ \\ Department of Materials Science and Engineering, Ajou University, Suwon 443-749, Korea \\ (Received September 10, 2011; Revised September 21, 2011; Accepted September 22, 2011)

\section{열분해 공정을 통해 합성된 산화 코발트 나노입자의 리튬 전기화학반응성 \\ 진연호· 심현우·김동완 ${ }^{\dagger}$ \\ 아주대학교 재료공학과 \\ (2011년 9월 10일 접수 ; 2011년 9월 21일 수정 ; 2011년 9월 22일 채택)}

\begin{abstract}
Nano-sized cobalt (II) oxide nanoparticles with a high crystallinity were synthesized using thermolysis of a $\mathrm{Co}^{2+}$-oleate precursor at $310^{\circ} \mathrm{C}$. The phase and morphology of as-prepared cobalt oxide nanoparticles were characterized using X-ray diffraction, highresolution transmission electron microscopy, and Brunauer-Emmett-Teller surface area measurements. The cobalt oxide nanoparticles were found to be spherical nanoclusters with an average diameter of approximately $200 \mathrm{~nm}$, consisting of tiny nanocrystals (10-20 nm). Furthermore, the Li electroactivites of the cobalt oxide nanoparticles were investigated using cyclic voltammetry and galvanostatic cycling. The cobalt oxide nanoparticles could deliver high capacities over $420 \mathrm{~mA} \mathrm{~h} \mathrm{~g}^{-1}$ at a C/5 current rate.
\end{abstract}

Key words : Cobalt oxides, Thermolysis, Nanoparticles, Electroactivity, Capacity

\section{1. 서 론}

최근, 에너지 저장 장치로써 리튬이온 이차전지가 주목 을 받으면서, 리튬이온 이차전지의 고성능화를 위한 재료 연구들이 다양한 분야 (전극, 분리막, 전해질 등)에서 활발 히 이루어지고 있다. 이 중, 전극 (양극, 음극) 소재는 리 튬이온 이차전지의 사이클 안정성 및 용량 특성 등의 전 기화학적 성능을 향상 시킬 수 있는 핵심 요소 중 하나로, 현재까지도 많은 연구들이 진행되고 있다. 근래 들어, 다 양한 조성의 나노구조체들을 리튬이온 이차전지의 전극 소재로 활용함으로써 향상된 전기화학적 특성을 보고하는 사례들이 증가하고 있다. 특히, 음극소재의 경우 현재 상 용화되고 있는 graphite 소재의 낮은 이론용량으로 (graphite 이론용량 : $372 \mathrm{~mA} \mathrm{~h} \mathrm{~g}^{-1}$ ) 인한 고에너지 특성 구현의 어 려움을 다양한 조성의 나노구조체들을 이용해 해결하려는 연구들이 활발히 이루어지고 있다.

2000년 Tarascon 그룹에서 나노크기 전이금속 산화물의 리튬이온 이차전지 음극소재 활용을 최초로 보고한 이 후, ${ }^{1)}$ 지금까지 다양한 조성의 전이금속 산화물들이 리튬이온

${ }^{\dagger}$ Corresponding author: Dong-Wan Kim

E-mail : dwkim@ajou.ac.kr

Tel : +82-31-219-2468 Fax : +82-31-219-3248
이차전지의 고용량 음극소재로 연구되고 있다. 이는 벌크 소재에 비해 나노크기의 재료가 갖는 높은 비표면적 특성을 바탕으로 리튬과의 활성 증가로 향상된 전기화학적 성능을 보일 수 있기 때문이다. 이러한, 전이금속 산화물들은 기존 의 graphite 소재처럼 리튬과의 삽입/탈리 반응이 아닌, 전환 반응 $\left(\mathrm{M}_{\mathrm{x}} \mathrm{O}_{\mathrm{y}}+n \mathrm{e}^{-}+n \mathrm{Li}^{+} \leftrightarrow x \mathrm{M}^{0}+\mathrm{Li}_{\mathrm{x}} \mathrm{O}_{\mathrm{y}}\right)$ 을 통해 용량 특성을 나타내며, 2 4개의 리튬이 반응에 참여하여 고용량의 특 성을 구현할 수 있다.

산화 코발트는 리튬이온 이차전지 음극소재로 응용될 수 있는 대표적인 전이금속 산화물 중 하나이다. 이러한 산화 코발트는 높은 이론 용량 (Cobalt (II) oxide 이론 용량 = $\left.715 \mathrm{~mA} \mathrm{~h} \mathrm{~g}^{-1}\right)$ 을 바탕으로 현재 상용화되어 있는 graphite 소 재에 비해 약 2 배 이상의 고용량 특성을 나타낼 수 있기 때 문에, ${ }^{2)}$ 지금까지 다양한 방법으로 합성이 시도되고 있으 나, ${ }^{3,4)}$ 아직까지 단일상의 코발트 (II) 산화물 나노구조체를 얻는 것에는 어려움이 있다. 본 논문에서는 높은 비등점을 갖 는 용매 내에서 $\mathrm{Co}^{2+}$-oleate 전구체를 열분해 시키는 방법을 이용하여 단일상의 코발트 (II) 산화물 나노입자를 합성하였 다. 합성된 코발트 (II) 산화물 나노구조체는 높은 결정성과 더불어 작은 나노입자들이 응집된 구형의 형상을 나타냈다. 또한, 본 연구에서는 합성된 코발트 (II) 산화물 나노구조체 들의 리튬 전기화학반응성 분석 및 특성 평가를 진행하였다. 


\section{2. 실험방법}

열분해 공정을 이용한 코발트 (II) 산화물 나노입자 합 성은 i) $\mathrm{Co}^{2+}$-oleate 전구체를 만드는 공정과 ii) 전구체의 열분해 반응 공정으로 단계화할 수 있다. 먼저, $18 \mathrm{mM}$ 의 $\mathrm{CoCl}_{2}$ (Anhydrous, Sigma-Aldrich, $98 \%$ )와 $48 \mathrm{mM}$ 의 Sodium oleate $\left(\mathrm{CH}_{3}\left(\mathrm{CH}_{2}\right)_{7} \mathrm{CH}=\mathrm{CH}\left(\mathrm{CH}_{2}\right)_{7} \mathrm{COONa}\right.$, Sigma-Aldrich, $95 \%$ )를 $60 \mathrm{~mL}$ 의 hexane, $20 \mathrm{~mL}$ 의 증류수 그리고 $20 \mathrm{~mL}$ 의 ethyl alcohol이 혼합되어 있는 용액에 서서히 녹인 후, 외부 공기와 차단된 밀폐된 상태로 $60^{\circ} \mathrm{C}$ 에서 4 시간 동안 반응 시킨다. 이 후, 층 분리가 이루어진 용액에서 보라색의 상등 액 부분만을 분리하고, 분리된 상등액은 $110^{\circ} \mathrm{C}$ 건조를 통해 용매를 완전 증발시킨다. 이 후, $\mathrm{Co}^{2+}$-oleate 전구체를 얻을 수 있다. $\mathrm{Co}^{2+}$-oleate 전구체는 열분해 과정을 통해 최종 코 발트 (II) 산화물로 합성될 수 있다. $\mathrm{Co}^{2+}$-oleate 전구체 $15 \mathrm{~g}$ 을 3구-플라스크에 옮겨 담은 후, $1.5 \mathrm{~g}$ 의 oleic acid와 $60 \mathrm{~mL}$ 의 1-octadecene을 함께 넣고 질소 분위기 내에서 $10^{\circ} \mathrm{C} / \mathrm{min}$ 의 가열 속도로 $310^{\circ} \mathrm{C}$ 까지 올린다. 이 후, 30 분간의 반응을 거쳐 형성된 고점도의 젤을 hexane과 ethyl alcohol이 $3: 1$ 의 비율로 혼합되어 있는 용액을 이용하여 세척하고 진공 오븐 에서 건조 과정을 통해 최종 분말을 회수할 수 있다.

합성된 나노분말은 X-선 회절 (XRD;Model: D/max-2500, Rigaku, Japan)과 투과전자현미경 (TEM; Model : JEM-3000F, JEOL, Japan), 고해상도의 투과전자현미경 (HRTEM)을 이용 하여 결정상 및 형상을 확인하였다. 또한 Brunauer-EmmettTeller (BET; Belsorp-mini, BEL Japan Inc., Japan) 측정을 통하여 비표면적을 분석하였다. 추가적으로, 합성된 코발트 (II) 산화물 나노구조체의 리튬 전기화학반응성을 알아보기 위해 반쪽 전지를 이용하여 전기화학적 특성 평가를 수행 하였다. 측정 시 사용된 전극은, 합성된 코발트 (II) 산화물 나노분말을 활물질로 적용하여, 결합제 (PVDF)와 도전제 (Super-P)가 각각 70:15:15의 비율로 혼합된 분말을 1methyl-2-pyrrolidinone (NMP; Sigma-Aldrich, 95\%)에 분산 시켜 슬러리로 만든 후, 구리 호일에 고르게 도포하고 건조 하는 것을 통해 제조될 수 있다. 또한, 리튬 금속을 음극으 로 사용하고 제조된 전극을 양극으로 적용하여 알곤 분위 기의 글로브 박스 안에서 전지를 조립하였다. 조립된 전지 들은 $0.01 \mathrm{~V} 3 \mathrm{~V}$ 까지의 작동 전압 하에서 순환전압 및 정 전류 방식의 측정을 진행하였다.

\section{3. 결과 및 고찰}

Fig. 1은 본 연구에서 코발트 (II) 산화물 나노입자를 획득 하기 위해 진행된 열분해 공정 모식도를 나타낸다. 코발트 (II) 산화물 합성을 위해 수행된 열분해 방법은 결정성이 매우 좋은 나노크기 입자들이 단분산되는 특징을 가지고 있으며, 대량생산이 가능한 공정으로 알려져 있다. ${ }^{5-7)}$ 모

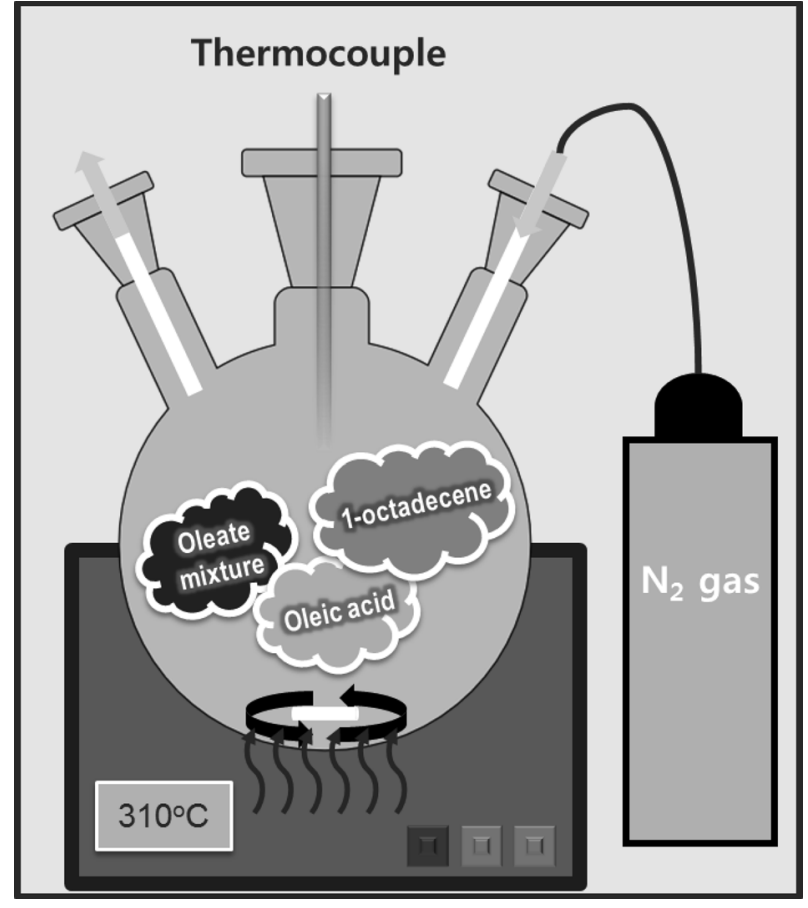

Fig. 1. Schematic illustration of thermolysis process.

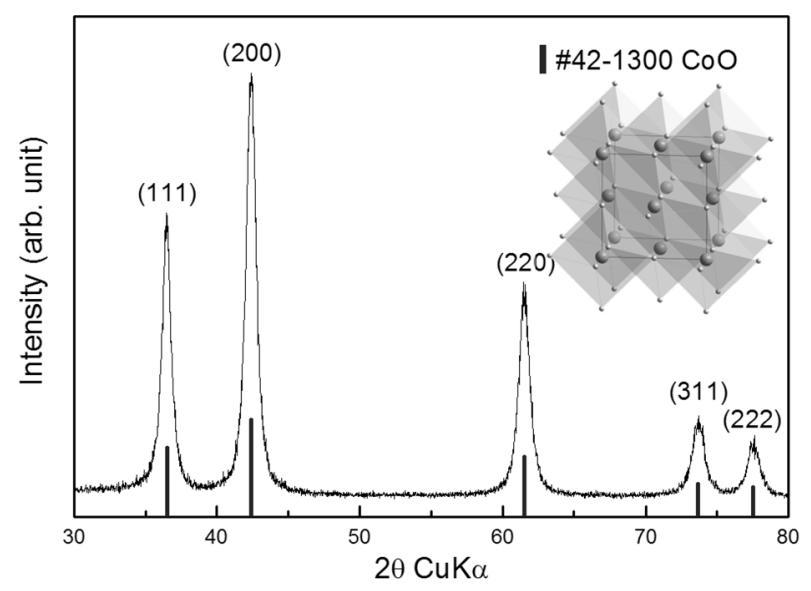

Fig. 2. XRD patterns of as-synthesized cobalt (II) oxide nanoparticles. Inset shows schematic crystal structure of cobalt (II) oxide.

식도에 나타낸 것처럼, 코발트 (II) 산화물 나노입자들은 미 리 준비된 $\mathrm{Co}^{2+}$-oleate 전구체들을 $310^{\circ} \mathrm{C}$ 에서 30 분간 진행 하는 것으로 얻어질 수 있으며, 반응 후 획득된 코발트 (II) 산화물들은 고점도성을 갖는 검은색의 젤과 같은 형태였다.

세척과 건조 과정을 거쳐 획득된 최종 분말의 결정상을 파악하기 위해, X-선 회절 분석을 진행하였다. Fig. 2의 XRD 패턴에서 보인 것처럼, 합성된 최종 분말은 높은 결정성과 더불어 $\mathrm{CoO}$ 의 결정 구조와 일치하는 것을 확인할 수 있었 다 [JCPDS card no. 42-1300 (Cobalt (II) oxide, F-43 m)]. 코발트 (II) 산화물 이외의 안정상으로 알려져 있는 코발트 
(II,III) 산화물 및 코발트 금속 등의 이차상들을 나타내는 peak들은 확인되지 않았으며, 이를 통해 $\mathrm{Co}^{2+}$-oleate 전구 체의 열분해 공정을 통해 단일상의 코발트 (II) 산화물을 쉽게 합성할 수 있음을 알 수 있다.

합성된 코발트 (II) 산화물의 보다 정밀한 관측을 위해 TEM 및 HRTEM 분석을 진행하였다. Fig. 3은 합성된 코발 트 (II) 산화물 나노구조체들의 대표적인 TEM 및 HRTEM 이미지를 나타낸다. TEM 분석으로부터 확인할 수 있듯이, 합성된 코발트 (II) 산화물 나노구조체들은 $10 ~ 20 \mathrm{~nm}$ 의 작은 나노입자들이 응집되어 구형의 코발트 (II) 산화물 나노클 러스터를 형성하는 것을 알 수 있다 (Fig. 3 (a), (b)). 또한, 형성된 나노클러스터들은 대부분 약 $200 \mathrm{~nm}$ 의 균일한 크기 를 나타냈으며, 응집된 작은 나노입자들 사이 공극들의 존 재를 확인할 수 있었다. 이에 합성된 코발트 (II) 산화물 분 말의 $\mathrm{BET}$ 측정을 통해 비표면적을 확인해 본 결과 약 $30 \mathrm{~m}^{2} \mathrm{~g}^{-1}$ 의 비교적 높은 비표면적 값을 나타내었다.

특히 이러한 단분산된 코발트 (II) 산화물 나노입자들의 합성은 $\mathrm{Co}^{2+}$-oleate가 이루는 구조 형태로부터 유도될 수 있다. 일반적으로 알려진 것처럼 metal-oleate의 전구체들은 고분자 사슬 (oleate 부분) 말단에 금속 이온들이 결합되어 있는 형태의 구조를 나타낸다. 이러한 metal-oleate 전구체들 은 유기 용매 내에서 분산되어 micelle의 형태를 나타내며, 온도를 높여 고분자 사슬을 제거하게 되면, 결과적으로 단 분산된 금속 이온들로만 구성된 산화물이 핵 생성 및 성장 을 거쳐 나노입자를 얻을 수 있게 된다.

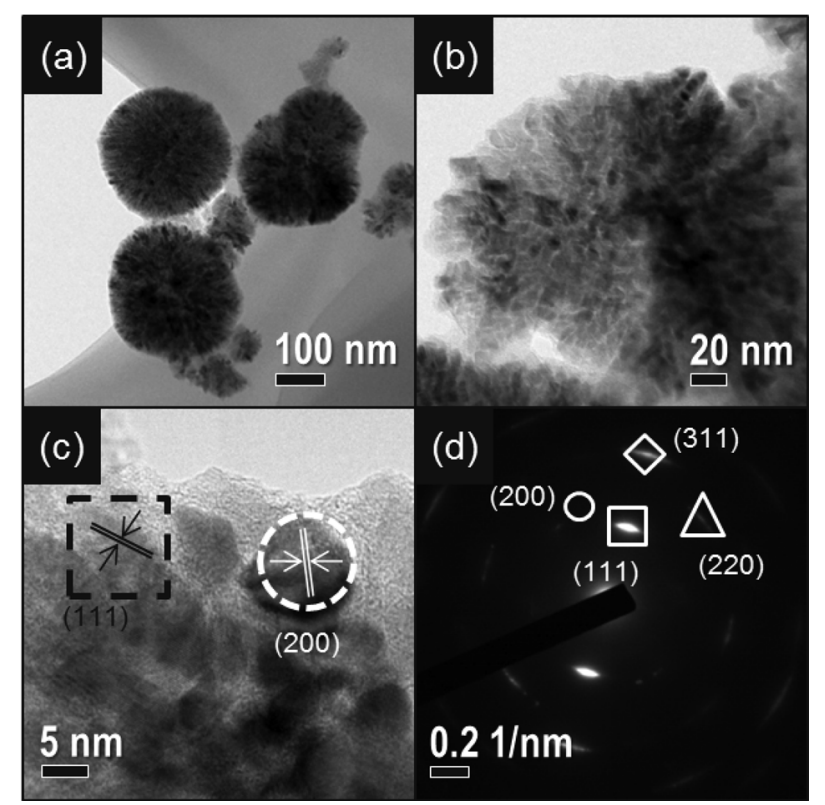

Fig. 3. Typical TEM images of cobalt (II) oxide nanoparticles. $(a, b)$ Low- and high-magnification TEM images of cobalt (II) oxide nanoparticles and (c,d) HRTEM image and corresponding SAED pattern of an individual nanoparticle.
Fig. 3(c)와 (d)는 각각 코발트 (II) 산화물 나노구조체의 HRTEM 분석 이미지 및 selected area electron diffraction (SAED) 패턴을 나타낸다. Fig. 3(c)에서 확인할 수 있듯이, 코발트 (II) 산화물 나노클러스터를 이루는 작은 나노입자들 은 콘 (cone) 모양의 형태를 나타내며 각각 높은 결정성을 갖는 것을 알 수 있다. 또한 SAED 패턴 분석 결과 이러한 코발트 (II) 산화물 나노입자는 다결정 (poly crystalline)의 형태를 나타냄을 확인할 수 있었다. 특히, HRTEM 이미지 및 SAED 패턴 결과들로부터 면간 거리를 측정한 결과 검 정색 점선으로 표기된 사각형 부분은 면간 거리가 $0.251 \mathrm{~nm}$ 로 (111) 면과 일치하며, 흰색 점선의 원형 부분은 $0.221 \mathrm{~nm}$ 로 (200) 면에 일치하는 것을 확인할 수 있다. 더욱이 이러 한 결과들은 Fig. 2에서 보인 X-선 회절 패턴의 결과들과 잘 상응하는 것을 알 수 있다.

본 연구에서는 합성된 코발트 (II) 산화물 나노구조체의 리틈 전기화학반응성을 평가하기 위해 순환전압법 (cyclic voltammetry, $\mathrm{CV}$ ) 분석을 진행하였다 (Fig. 4). 분석된 $\mathrm{CV}$ 그래프는 $0.1 \mathrm{mV} \mathrm{s}^{-1}$ 의 주사속도로 $0.01 \sim 3 \mathrm{~V}$ 의 전압 사이를 10 사이클 반복시켜 측정하였다. $\mathrm{CV}$ 그래프에 나타난 것 처럼, 첫 번째 사이클 진행간 $1 \mathrm{~V}$ 이하의 낮은 전압에서 최 초 리튬이 삽입되는 환원 peak이 나타났으며, $1.4 \mathrm{~V}$ 와 $2.1 \mathrm{~V}$ 에서 두 개의 산화 peak들이 나타났다. 이 후, 두 번째 사이 클 진행부터는 $1.3 \mathrm{~V}$ 와 $1.1 \mathrm{~V}$ 에서 각각의 환원 peak들이 관찰되면서, 첫 번째 사이클에서 보였던 $1.4 \mathrm{~V}$ 와 $2.2 \mathrm{~V}$ 의 산화 peak들과 산화/환원 반응의 쌍을 이루며 충 - 방전 사이클이 진행됨을 알 수 있다. 이러한 코발트 (II) 산화물 나노입자의 $\mathrm{CV}$ 결과는 이전에 발표된 산화 코발트 전극에 서 보고된 경향과 유사한 형태임을 확인하였다. ${ }^{8)}$

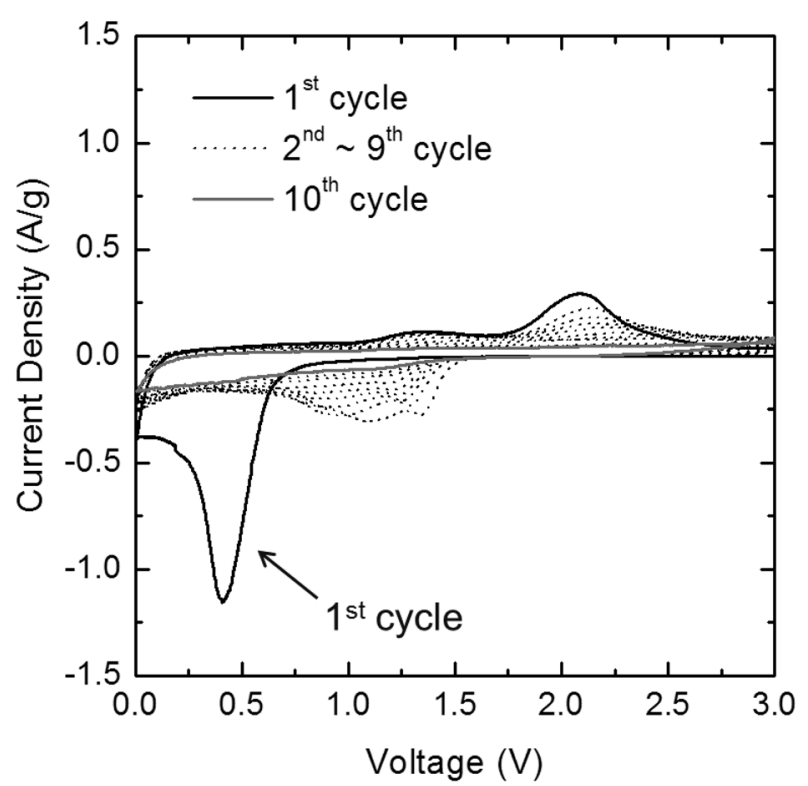

Fig. 4. Cyclic voltammetry of the cobalt (II) oxide nanoparticles in the first ten cycles. 
앞서 언급한 것처럼, 전이금속 산화물들의 경우 리튬과의 전환반응 메커니즘을 통해 용량 특성을 나타낼 수 있다. 일반적으로 알려진 코발트 (II) 산화물의 경우 리튬과의 충-방전간 발생하는 반응은 아래의 식과 같이 나타낼 수 있으며, ${ }^{9)}$ 이를 바탕으로 계산된 이론용량을 통해 정전류 측정 방식에서 주입하는 전류 밀도를 계산할 수 있다.

$$
\mathrm{CoO}+2 \mathrm{Li}^{+}+2 \mathrm{e}^{-} \leftrightarrow \mathrm{Li}_{2} \mathrm{O}+\mathrm{Co}
$$

Fig. 5는 합성된 코발트 (II) 산화물 나노구조체의 정전 류 방식으로 측정된 충·방전 그래프를 나타낸다. $0.01 \sim 3 \mathrm{~V}$ 사이의 작동 전압 구간에서 $\mathrm{C} / 5$ 의 전류 밀도로 $\left(143 \mathrm{~mA} \mathrm{~g}^{-1}\right)$ 수행된 측정 결과, 첫 번째 방전 용량은 $1262 \mathrm{~mA} \mathrm{~h} \mathrm{~g}^{-1}$ 을 나타냈다. 특히, 리틈이 삽입되는 첫 번째 사이클의 plateau 는 $1 \mathrm{~V}$ 이하의 $0.5 \mathrm{~V}$ 부근에서 일어나며, 이는 Fig 4에서 보인 CV 그래프의 첫 번째 방전 시 나타나는 환원 peak의 전압과 일치한다. 또한 첫 번째 방전 특성과 충전 특성 사이에서 큰 비가역적인 용량의 차이를 확인할 수 있었 으며, 이 후, 충·방전 사이클이 진행되면서 용량의 감소가 점진적으로 발생했다. 이러한, 초기 비가역적인 용량 발생은 충·방전 사이클 진행간 형성되는 solid-electrolyte interface (SEI) 층의 형성과 관련된다. ${ }^{10)}$ 이후, 사이클이 진행되면서 용량의 감소를 보이지만, 10 번째 사이클이 진행된 후에도 코발트 (II) 산화물 나노구조체 전극은 약 $420 \mathrm{~mA} \mathrm{~h} \mathrm{~g}^{-1}$ 의 높은 가역적 용량 특성을 나타내었다. 사이클 진행에 따른 용량 감소는 전극 활물질을 제조하는 과정에서 발생하는 불완전한 혼합 및 합성된 코발트 (II) 산화물 나노입자들의 응집 현상으로 입자간 접촉 저항이 증가하여 리틈이온이

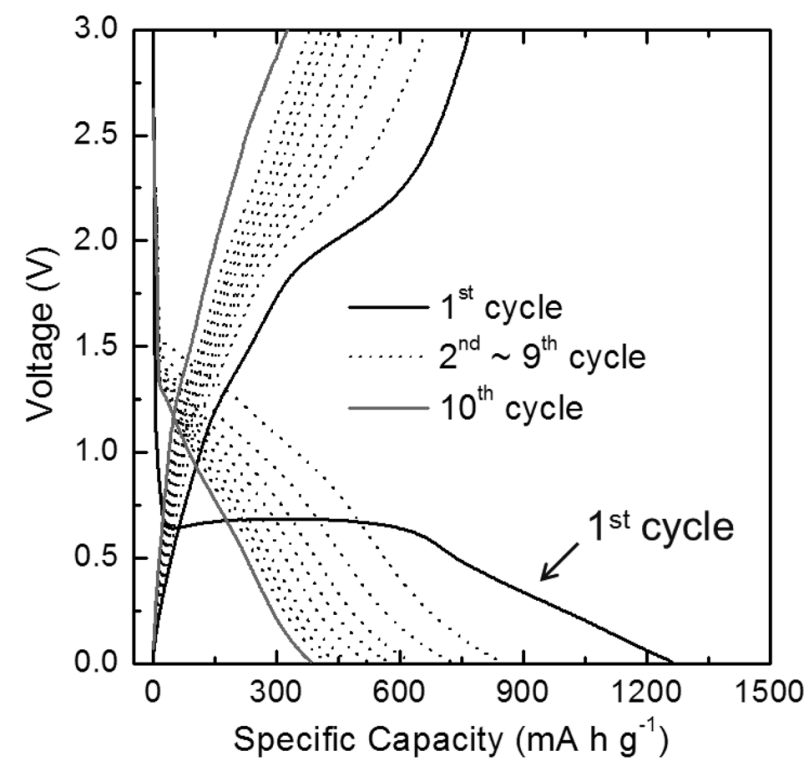

Fig. 5. Charge-discharge profiles of the electrode made from the as-prepared cobalt (II) oxide nanoparticles.
활물질에 개별적으로 반응하지 못해 용량 감소가 일어나는 것으로 생각될 수 있다. ${ }^{10)}$ 따라서, 전극 재료의 효과적인 혼합과 함께 나노크기의 물질들의 응집 효과를 제거하고 고전자 전달을 유도할 수 있는 표면 개질을 수반한다면 더 좋은 용량 특성을 기대해 볼 수 있다.

\section{4. 결 론}

본 논문에서는 $\mathrm{Co}^{2+}$-oleate 전구체들을 열분해 시키는 공정을 통해 단일상의 코발트 (II) 산화물 나노입자들을 합 성하였다. 합성된 코발트 (II) 산화물 나노입자들은 $10-20 \mathrm{~nm}$ 의 작은 콘 모양 형상을 보였으며, $\mathrm{XRD}$ 및 $\mathrm{TEM}$ 분석 결과 높은 결정성과 함께 단일상의 $\mathrm{CoO}$ 구조를 나타냈다. 특히, 합성된 나노입자들은 서로 응집되어 구형의 나노클러스 터들을 형성하였다. 형성된 나노클러스터들은 약 $200 \mathrm{~nm}$ 직경의 균일한 크기를 보였다. 이러한 코발트 (II) 산화물 나노구조체를 이용해 제조된 전극은 $\mathrm{C} / 5$ 의 전류 밀도에서 이루어진 리틈과의 전기화학적 특성 평가 결과, 10 사이클 의 충·방전 후에도 약 $420 \mathrm{~mA} \mathrm{~h} \mathrm{~g}$ 의 높은 가역적인 용량 특성을 보이며, 상용화되고 있는 graphite 음극소재에 비해 높은 용량 특성을 나타내었다.

\section{Acknowledgment}

이 논문은 2011년도 교육과학기술부의 재원으로 한국 연구재단의 지원을 받아 수행된 연구임. (No. 2011-0005776, 2010-0029617)

\section{REFERENCES}

1. P. Poizot, S. Laruelle, S. Grugeon, L. Dupont, and J. M. Tarascon, "Nano-sized Transition-metal Oxides as Negativeelectrode Materials for Lithium-ion Batteries," Nature, $\mathbf{4 0 7}$ [28] 496-99 (2000).

2. C. H. Chen, B. J. Hwang, J. S. Do, J. H. Weng, M. Venkateswarlu, M. Y. Cheng, R. Santhanam, K. Ragavendran, J. F. Lee, J. M. Chen, and D. G. Liu, "An Understanding of Anomalous Capacity of Nano-sized $\mathrm{CoO}$ Anode Materials for Advanced Li-ion Battery," Eletrochem. Commun., 12 496-98 (2010).

3. Y. Ye, F. Yuan, and S. Li, "Synthesis of CoO Nanoparticles by Esterification Reaction Under Solverthermal Conditions," Mater. Lett., 60 3175-78 (2006).

4. N. A. M. Barakat, M. S. Khil, F. A. Sheikh, and H. Y. Kim, "Synthesis and Optical Properties of Two Cobalt Oxides $\left(\mathrm{CoO}\right.$ and $\left.\mathrm{Co}_{3} \mathrm{O}_{4}\right)$ Nanofibers Produced by Electrospinning Process," J. Phys. Chem. C, 112 12225-233 (2008).

5. K. An, N. Lee, J. Park, S. C. Kim, Y. Hwang, J. G. Park, J. Y. Kim, J. H. Park, M. J. Han, J. Yu, and T. Hyeon, "Synthesis, Characterization, and Self-assembly of Pencil-shaped $\mathrm{CoO}$ Nanorods," J. Am. Chem. Soc., 128 9753-60 (2006). 
6. J. Park, K. An, Y. Hwang, J. G. Park, H. J. Noh, J. Y. Kim, J. H. Park, N. M. Hwang, and T. Hyeon, "Ultra-large-scale Syntheses of Monodisperse Nanocrystals," Nature Mater., 3 891-95 (2004).

7. N. Bao, L. Shen, W. An, P. Padhan, C. H. Turner, and A. Gupta, "Formation Mechanism and Shape Control of Monodisperse Magnetic $\mathrm{CoFe}_{2} \mathrm{O}_{4}$ Nanocrystals," Chem. Mater., 21 3458-68 (2009).

8. J. S. Do and C. H. Weng, "Electrochemical and Charge/discharge Properties of the Synthesized Cobalt Oxide as Anode
Material in Li-ion Batteries," J. Power Sources, 159 323-27 (2006).

9. G. X. Wang, Y. Chen, K. Konstantinov, M. Lindsay, H. K. Liu, and S. X. Dou, "Investigation of Cobalt Oxides as Anode Materials for Li-ion Batteries," J. Power Sources, 109 142-47 (2002).

10. G. H. Lee, J. G. Park, Y. M. Sung, K. Y. Chung, W. I. Cho, and D. W. Kim, "Enhanced Cycling Performance of an $\mathrm{Fe}^{0} / \mathrm{Fe}_{3} \mathrm{O}_{4}$ Nanocomposite Electrode for Lithium-ion Batteries," Nanotechnology, 20 295205-209 (2009). 